\section{Necrotising Fasciitis - A Rare Complication of Percutaneous Endoscopic Gastrostomy}

A 63-year-old woman suffered two successive cerebrovascular accidents which resulted in progressive dysphagia: she had begun to choke on liquids and solids. After a preliminary gastroscopy to rule out mechanical problems, a 12-Fr percutaneous endoscopic gastrostomy (PEG) (Bower, E. Merck, Alton, Hants) was inserted through a $5 \mathrm{~mm}$ skin incision using the Gauderer-Ponsky technique (1). The surgeon and his assistant scrubbed with an antiseptic and wore sterile gloves; the anterior abdominal wall was painted with an antiseptic and draped; and antibiotics were not given. On the third postoperative day erythema of the skin around the gastrostomy accompanied by a brown discharge was noticed. A swab from this grew mixed coliforms, enterococci and anaerobes. Despite broadspectrum antibiotics she suffered from endotoxinemia and developed a myofasciitis of the abdominal wall. During the operation the gastrostomy tube was not displaced, and the stomach was well apposed to the abdominal wall. The tube was removed, the stomach closed, and the abdominal wall debris removed. With parenteral and later nasogastric feeding she made an uneventful recovery, with a secondary wound healing after three months.

Necrotising fasciitis has been reported in only four patients who underwent a PEG (2-5), three of whom died. The striking common factor was that neither these four patients nor the patient presented here received prophylactic antibiotics. Previously reported risk factors for developing this complication (diabetes mellitus, alcoholism, chronic renal failure, and pulmonary tuberculosis) $(2-5)$ were not present.

We have now changed our practice to include a single dose of prophylactic antibiotic before PEG insertion. Also, as the $5 \mathrm{~mm}$ skin incision may have prevented adequate drainage from the subcutaneous plane, we now favour a larger incision.

D. A. Evans, D. S. Bhandarkar, T. V. Taylor

The Department of Surgery, Manchester Royal Infirmary, Oxford Road, Manchester, United Kingdom

\section{References}

1. Gauderer MW, Ponsky JL, Izant RJ: Gastrostomy without laparotomy: a percutaneous endoscopic technique. J Paed Surg $1980 ; 15: 872-875$.

2. Greif $J M$, Ragland $J J$, Ochsner $M G$, et al.: Fatal necrotising fasciitis complicating percutaneous endoscopic gastrostomy. Gastrointest Endosc 1986; 32: 292-294.

3. Cave DR, Robinson WR, Brotschi EA: Necrotising fasciitis complicating percutaneous endoscopic gastrostomy. Gastrointest Endosc 1986; 32: 294-296.

4. Person $J L$, Brower RA: Necrotising fasciitis/myositis following percutaneous endoscopic gastrostomy. Gatrointest Endosc 1986; 32: 309 .

5. Korula J, Rice HE: Necrotising fasciitis complicating percutaneous endoscopic gastrostomy. Gastrointest Endosc. 1987; 33: $335-336$.

Corresponding Author

D. A. Evans, M.D.

32 Bamford Road

Didsbury, Manchester, M20 2GW

United Kingdom 